14-16 May, 2021

Paris, France $12^{\text {th }}$ International Conference on

Humanities, Psychology \& Social Sciences

\title{
The mediating effect of emotional intelligence on the big five personality traits and the big six vocational interests
}

\author{
Mayiana Mitevska, Paulina Tsvetkova \\ University of Library Studies and Information Technologies, 119 "Tsarigradsko shose” blvd., Sofia \\ Plovdiv University "Paisii Hilendarski”, 24 “Tsar Asen” str,. Plovdiv 4000, Bulgaria
}

\begin{abstract}
.
A central theme in the present study is the assumption that the influence on human behaviour is mediated by different internal processes in the career choice. Emotional intelligence is defined as a variable which is a cause for the relationship between personality traits and the choice of a certain career. Three causal paths to the dependent variable were tracked - a path to the direct impact of the emotional intelligence on the career choice, a path to the influence of personality traits on the emotional intelligence as well as a path to the impact of personality traits on the career choice via the emotional intelligence. The aim of the study was to show the mediating role of emotional intelligence in the relationship between personality traits and career choice. A total of 100 Bulgarian secondary and university students (42 males and 58 females), aged 17-40 years, were included in the research. The following measures were used for the purpose of the study - Trait Emotional Intelligence Questionnaire - Short Form (TEIQue-SF), The Big five questionnaire and the Big six method for career choices. The results showed that there was a direct positive impact of the emotional intelligence on the relationship between the enterprising type and conscientiousness, the artistic type and neuroticism and a negative impact on the relationship between the conventional type and extraversion. The conclusions derived from the study could be used for further psychological research in the field, as well as for enhancing the knowledge of one's personality.
\end{abstract}

Keywords: secondary students, university students, mediation

\section{Introduction}

Nowadays there is a significant interest in the impact of individual variables, such as personality traits, regarding career choices. Originally, the question of personality match with career choice has been examined by J.Holland who suggested that vocational interests reflect individuals' personality and skills, and decisions about career choices are influenced by personality characteristics (Holland, 1959). In addition, the career development literature has increasingly focused on the role played by emotions in the career decision-making processes (Emmerling \& Cherniss, 2003). Cooper (Cooper, 1997) reported that those who trust their own feelings seem to have more successful career paths. Within the framework of these studies, a reference can be made to emotional intelligence which has drawn great attention in the scientific 


\section{4-16 May, 2021 \\ Paris, France}

\section{$12^{\text {th }}$ International Conference on Humanities, Psychology \& Social Sciences}

field for the last two decades. Interest in the emotional intelligence originated from the fact that, while personality characteristics are considered essentially stable, it can be increased through specific training (Bar-On, 1997, 2002; Mayer \& Salovey, 1997). The objectives of the study are to determine the mediating effect of the emotional intelligence on the big five personality traits and the big six vocational interests and to show the extent to which the factors of the emotional intelligence impact them. It is hypothesized that there is a significant influence of the emotional intelligence on the relationship between the personality traits and the career preferences. For the purpose of the study a mediation analysis has been used and the emotional intelligence is the mediator variable in it.

\section{Methods}

\subsection{Procedure}

Questionnaires were distributed in several schools and universities both online and paper versions. Participants were informed that this study was confidential and voluntary. The study was conducted between October and December 2020.

\subsection{Participants}

The sample consisted of 100 adolescents and adults in early adulthood (42\% males, $58 \%$ females). $56 \%$ of them are from 17 to 19 years and $44 \%$ of the participants are from 20 to 40 years. Respondents' mean age is 19 years.

\subsection{Measures}

The first questionnaire - The Big Five questionnaire - is a 20-item short form of the 50-item International Personality Item Pool-Five-Factor Model measure (Goldberg, L. R., 1999) and was developed by Donnellan and colleagues (Donnellan et al., 2006). The questionnaire measures five traits- extraversion, agreeableness, conscientiousness, neuroticism, openness- and consists of 20 items with a 5-point scale, ranging from 1 ("it doesn't apply to me at all") to 5 ("it completely applies to me"). For the purpose of this research paper, we have used a version, adapted for Bulgarian conditions by S. Karabelyova (Karabeliova, 2015) .The second questionnaire was created by Ch.Nybakken, G. Siegel and K. Ferlazzo (Nybakken, Siegel, Ferlazzo, 2003). It is a method for career choices and is based on the theoretical model of John Holland for the Big Six Vocational Interests ( Holland, J., 1959) The six career preferences are realistic, investigative, artistic, social, enterprising and conventional. It was adapted for Bulgarian sociocultural context by S. Karabeliova (Karabeliova, 2015). The Bulgarian version comprised 48 statements responded to on a 4-point scale, ranging from 1 ("it doesn't apply to me at all") to 4 ("it completely applies to me"). The third questionnaire - Trait Emotional Intelligence Questionnaire - Short Form (TEIQue-SF) - was used for the purpose of the study. Its author is Petrides whose model reflects the subjective processes of emotional experiences and perceptions of the inner world (Petrides, K. V., 2009). The factors of the questionnaire are well-being, self-control, emotionality and sociability. It contains 
14-16 May, 2021

Paris, France $12^{\text {th }}$ International Conference on

Humanities, Psychology \& Social Sciences

30 statements with a 7-point scale, ranging from 1 ("it doesn't apply to me at all") to 7 ("it completely applies to me"). The questionnaire was translated in Bulgarian by Antonina Kardasheva (Kardasheva, 2012).

\section{Mediation analysis and results}

The results from the current study are shown in the following tables. Some personal variables have been studied in the role of predictors, the factors of emotional intelligence - in the role of mediators and the vocational interests have been studied as criterial variables. The coefficient in the area of the numerator shows the strength of the relationship between the independent and the dependent variables. The coefficients in the area of the denominator show the strength of the relationship between the independent and the dependent variables under the control of the respective mediator variable.

Table 1: Mediator influences of the factor well-being of the Emotional Intelligence on the Big Five Traits and the Big Six Vocational Interests Figure description

\begin{tabular}{|c|c|c|c|c|c|}
\hline BIG6 & 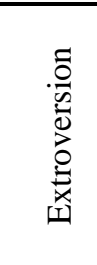 & 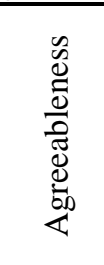 & $\begin{array}{l}0 \\
0 \\
0 \\
0 \\
0 \\
0 \\
0 \\
0 \\
0 \\
0\end{array}$ & 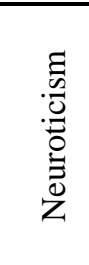 & 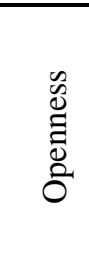 \\
\hline \multirow{2}{*}{ Realistic } & $\underline{-0.03}$ & $\underline{-0.06}$ & $.35^{* *}$ & $\underline{-0.03}$ & $\underline{0.17}$ \\
\hline & -0.06 & -0.09 & 0.35 & 0 & 0.15 \\
\hline \multirow{2}{*}{ Investigative } & -0.09 & $\underline{0.19}$ & $\underline{0.16}$ & $\underline{0.02}$ & $.29^{* *}$ \\
\hline & -0.16 & 0.15 & 0.11 & 0.1 & 0.26 \\
\hline \multirow{2}{*}{ Artistic } & $\underline{0.02}$ & $.42^{* * *}$ & $\underline{0.12}$ & $\underline{0.15}$ & $.46^{* *}$ \\
\hline & -0.06 & 0.39 & 0.04 & 0.26 & 0.43 \\
\hline \multirow{2}{*}{ Social } & $\underline{0.14}$ & $.57^{* * *}$ & $\underline{0.07}$ & $.23^{*}$ & $.40^{* *}$ \\
\hline & 0.04 & 0.54 & -0.05 & 0.4 & 0.35 \\
\hline \multirow{2}{*}{ Enterprising } & $.49^{* *}$ & $\underline{0.1}$ & $.21^{*}$ & $\underline{0}$ & $\underline{0.14}$ \\
\hline & 0.42 & 0 & 0.07 & 0.18 & 0.05 \\
\hline \multirow{2}{*}{ Conventional } & $\underline{-0.16}$ & $\underline{0.05}$ & $.39^{* *}$ & $\underline{0.01}$ & $\underline{0.04}$ \\
\hline & -0.27 & -0.02 & 0.33 & 0.14 & -0.02 \\
\hline
\end{tabular}

Note: In the denominator is the the correlation coefficient under the control of well-being as a factor of Emotional Intelligence

Table 2. Mediator influences of the factor sociability of the Emotional Intelligence on the Big Five Traits and the Big Six Vocational Interests

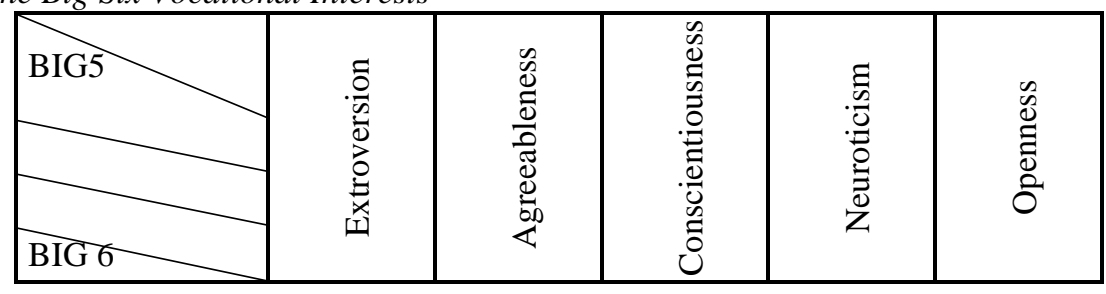


14-16 May, 2021

Paris, France $1^{\text {th }}$ International Conference on Humanities, Psychology \& Social Sciences

\begin{tabular}{|c|c|c|c|c|c|}
\hline BIG 6 & & & & & \\
\hline \multirow{2}{*}{ Realistic } & $\underline{-0.03}$ & $\underline{-0.06}$ & $.35^{* *}$ & $\underline{-0.03}$ & $\underline{0.17}$ \\
\hline & -0.08 & -0.11 & 0.32 & 0.03 & 0.14 \\
\hline \multirow{2}{*}{ Investigative } & $\underline{-0.09}$ & $\underline{0.19}$ & $\underline{0.16}$ & $\underline{0.02}$ & $.29^{* *}$ \\
\hline & -0.18 & 0.13 & 0.07 & 0.13 & 0.25 \\
\hline \multirow{2}{*}{ Artistic } & $\underline{0.02}$ & $.42^{* *}$ & $\underline{0.12}$ & $\underline{0.15}$ & $.46^{* *}$ \\
\hline & -0.09 & 0.36 & -0.02 & 0.31 & 0.41 \\
\hline \multirow{2}{*}{ Social } & $\underline{0.14}$ & $.57^{* *}$ & $\underline{0.07}$ & $.23^{*}$ & $.40^{* *}$ \\
\hline & 0.05 & 0.53 & -0.07 & 0.4 & 0.35 \\
\hline \multirow{2}{*}{ Enterprising } & $.49^{* * *}$ & $\underline{0.1}$ & $.21^{*}$ & $\underline{0}$ & 0.14 \\
\hline & 0.42 & -0.01 & 0.05 & 0.17 & 0.05 \\
\hline \multirow{2}{*}{ Conventional } & $\underline{-0.16}$ & $\underline{0.05}$ & $.39^{* *}$ & 0.01 & $\underline{0.04}$ \\
\hline & -0.25 & -0.02 & 0.33 & 0.12 & -0.02 \\
\hline
\end{tabular}

Note: In the denominator is the the correlation coefficient under the control of self-control as a factor of Emotional Intelligence

A direct significant relationship has been established, as shown in Table 1, between conscientiousness and the realistic and the conventional types; between agreeableness and the artistic and the social types; between neuroticism and the social type as well as between openness and the investigative, artistic and social types. The data show that the personality participates actively and consistently in the regulation of one's behavior and it can be assumed that some of the changes in most of the aspects of emotional intelligence are due to it. This is especially true for the innate, biologically determined traits, such as extraversion, but in fact it is the most manifested in openness, conscientiousness, and agreeableness as personality traits.

Being weak to moderate, the interrelationships with the different types of the Big Six Interests keep their significance, despite their interaction with the factors of the emotional intelligence. However, under the control of well-being there is a relatively strong change. Emotionally stable individuals probably seek and find satisfaction from emotionally unstable ones in different ways but this is a subject of another analysis, for example, a moderator one and that is why it has not been established in the present study. Despite being as weak as neuroticism, the interrelationships of purposefulness, as a feature of the Big Five Traits, also show stability of the relationship with the Big Six Interests, regardless of the impact of sociability, emotionality and self-control. In this particular case, it is interesting to trace the interrelations of the aforementioned three personality traits with which ones of the Big Six. The social type is influenced by each of the personality traits under the control of well-being as an element of emotional intelligence. The effect of well-being and self-control on the enterprising type is strong, followed by the conventional and the artistic types. The presence of opportunities for friendly and supportive relationships stimulates extroverts into choosing the enterprising type under the control of each of the factors of emotional intelligence. It can be argued that the result is logical, as the personality traits are relatively independent constructs. However, only well-being and self-control as elements of emotional intelligence have an effect 


\section{4-16 May, 2021 \\ Paris, France}

\section{$12^{\text {th }}$ International Conference on Humanities, Psychology \& Social Sciences}

on extraversion and aspects of job satisfaction, interpersonal communication and support of colleagues. The influence of emotional intelligence in the interaction between neuroticism with the career types is positive. The impact of sociability, emotionality and self-control on the realistic type is a little weaker. The results are congruent with results in previous research. Characteristics that refer to the emotionally unstable personality type do not have a significant direct effect on the aspects of emotionality which have been measured. In addition, conscientiousness is negatively related to the social type under the control of well-being and to the artistic type under the self-control. A slight influence of well-being on the investigative type has been observed.

In terms of the mediators - the aspects of emotional intelligence - it has been found that "well-being" has a direct positive effect on the realistic, artistic and enterprising types and a negative effect on the conventional type. The high level of job satisfaction is generally influenced by collectivist practices and contributes to cooperation, purposefulness and openness and is a reasonable ground for developing good work relationships and building trust with colleagues. The impact of "self-control" on the artistic, social and enterprising types is a bit weaker and affects negatively the interaction between agreeableness and the enterprising type, as well as the one between openness and the conventional type.

Taking into account the above-mentioned data, it can be suggested that assessments of the work environment and the competence significantly increase the emotional intelligence as a whole, if they have ego-relevant elements. They are alternative ways for people to support their professional self-esteem. The pleasure of one's competence probably contributes more directly to the maintenance of a positive self-image because self-expression is viewed as a prerequisite for achieving personal goals, which has been confirmed by other empirical data (Radoslavova, 2001). There is an opportunity for self-expression in every aspect of personality, except for neuroticism.

Emotional intelligence as a whole outlines significant mediating effects in the interaction between conscientiousness and openness with the career choices. The most direct positive effects on the independent variables - personality traits and mediators are related to the career preferences.

The current results for the direct and indirect impact of the independent variables and mediators on the career choices show a moderate dependence. Regarding the data for the career interests, the respondents have a coherent and coordinated system depending on personal characteristics - agreeableness, conscientiousness and openness.

In this sense, the assumption of the direct and indirect effects of the Big Five Traits on the career choices mediated by well-being and self-control was confirmed. They are important for self-expression and task orientation. The study proved the assumption that the factors of emotional intelligence are integrated into the behavior of individuals in terms of career preferences. 


\section{4-16 May, 2021 \\ Paris, France}

\section{$12^{\text {th }}$ International Conference on Humanities, Psychology \& Social Sciences}

\section{Conclusion}

The aims of the study were to determine the mediating effect of emotional intelligence on the big five personality traits and the big six vocational interests. The results validated our hypothesis. It was observed that there was a great positive and negative impact of the emotional intelligence on the relationship between some of the personality characteristics and some of the career preferences. The current research paper has some limitations. Firstly, iIt was conducted on a small sample. We recommend repeating the study with a larger sample. Secondly, it is necessary to examine test-retest correlations over a longer period of time to further clarify if the participants work in a field relevant to their personality traits and emotional intelligence. Despite this, the authors believe that the provided work has important implications for further research in the field of personality and organizational psychology. There will also be a subsequent analysis of gender, divided into three groups, and its influence will be traced. In conclusion, it can be said that career choices depend on a variety of permanent and situational factors which have a multidimensional structure. A comprehensive approach is needed to study these dependencies in detail. More precise theoretical models must be used so that more stable influences between psychological variables can be observed. A possible way out of the situation could be the use of structural models which provide much richer opportunities for determining trends. Checks for the mediating function, i.e. for the role of the third variable as a mediator for other variables included in the study, were made. They only confirm the claim that every single social phenomenon, as it was emphasized, is multifactorial. Some of the factors, however, manifest themselves in the role of the third variable, which mediates the relationship between the predictor and the output variable, and in this way it increases or decreases its influence on it.

\section{Acknowledgment}

The authors gratefully acknowledge University of Library Studies and Information Technologies which sponsored the conference participation.

\section{References :}

Bar-On, R. (1997). The emotional intelligence inventory (EQ-I): Technical manual. Toronto: Multi Health Systems.

Bar-On, R. (2002). Bar-On emotional quotient inventory: Short technical manual. Toronto: Multi-Health Systems.

Cooper, R. K. (1997). Applying emotional intelligence in the work place. Training and Development. 51(12), 31-38.

Donnellan, M. B., Oswald, F. L., Baird, B. M., \& Lucas, R. E. (2006). The MiniIPIP scales: Tiny-yet-effective measures of the Big Five factors of personality. Psychological Assessment, 18, 192- 203.

Emmerling, R. J., \& Cherniss, C. (2003). Emotional intelligence and career choice process. Journal of Career Assessment, 11(2), 153-167. 
14-16 May, 2021

Paris, France $12^{\text {th }}$ International Conference on Humanities, Psychology \& Social Sciences

Goldberg, L. R. (1999). A broad-bandwidth, public domain, personality inventory measuring the lower- level facets of several five-factor models. In I. Mervielde, I. Deary, F. De Fruyt, \& F. Ostendorf (Eds.), Personality Psychology in Europe, Vol. 7, 7-28. Tilburg, The Netherlands: Tilburg University Press.

Holland, J. L. (1959). A theory of vocational choice. Journal of Counseling Psychology, 6, 35-45.

Karabeliova, S. (2015). Career choice. Intercultural and intracultural comparisons. Klasika i stil. Sofia (in Bulgarian).

Kardasheva, A. (2012). Emotional intelligence and individual differences of Bulgarians. Sofia: Kovachev (in Bulgarian).

Mayer, J. D., \& Salovey, P. (1997). What is emotional intelligence? In P. Salovey $\&$ D. Sluyter (Eds.), Emotional development and emotional intelligence. 3-31. New York: Basic Books.

Nybakken, Ch., Siegel, G., \& Ferlazzo. C. (2003). Merging Two Worlds. Transition/Career Planning. Arizona: Arizona Department of Education.

Petrides, K. V. (2009). Psychometric properties of the Trait Emotional Intelligence Questionnaire. In C. Stough, D. H. Saklofske, and J. D. Parker. Advances in the assessment of emotional intelligence. $\quad$ New York: Springer. DOI: 10.1007/9780-387-88370-0_5

Radoslavova, M. (2011). Satisfaction with labour. Psychic mechanisms of occurrence and functions. Sofia, Paradigm, 2001, 45-58. 